\title{
Groningen in the European context
}

\author{
Ch. Burgos
}

Director-General, DGXVII (Energy), European Commission

40 years ago, when the Groningen gas field was discovered, it was impossible to foresee the impact and significance of the field both for The Netherlands as well as for Europe. In 1959, the Dutch gas reserves were estimated at around 60 billion cubic meters, which at the time caused excitement. Since then, the Dutch gas industry has brought some 2,000 billion cubic meters out of the ground and delivered these to customers on the domestic and export markets. Despite this, the remaining total expected gas reserves today are at around 2,500 billion cubic meters, which is enough to meet Gasunie's supply commitments at home and abroad until 2025, by which date several hundred billions of cubic meters would still be left in the ground. Only time will tell how these reserves will develop.

The role of the Groningen field in the buildup of an integrated European gas grid has been significant. Groningen has been one of the few giant gas fields or regional clusters of gas fields in Europe, which 30-40 years ago started a process of expansion and integration in the European gas sector.

Although declining in absolute annual output, the Groningen field is still the backbone of Dutch gas supply and will remain so far into the future. In addition, its swing capabilities will be maintained and it will be able to contribute to what the Dutch gas industry is so known for and capable of: providing flexibility.

Dutch gas exports to its neighboring countries started in 1965 and have increased ever since. Dutch gas will continue to play a pivotal role in Europe's gas supply also in the coming decades and not only in Western Europe, but also further to the east.

Representing more than $50 \%$ of the EU's gas reserves, Dutch gas reserves play an essential role in the European gas market and will contribute significantly both to the functioning of the internal gas market and to the EU's long-term security of supply of gas.

The European energy landscape is under rapid transformation these years with the internal energy market being completed. The entry into force in August 1998 of the Gas Directive will have a major impact on the organization of the European gas sector and the trade of gas. Change may happen sooner rather than later. The dynamics of the markets are already there and the EU Gas Directive will accelerate this.

The ambition goes beyond that of liberalizing $15 \mathrm{na}-$ tional gas markets. The objective is to create one single EU Market for gas and there is therefore a need to ensure, that the different choices, which will be made by Member States, are compatible with the overall objectives and principles of a Single Market.

The Commission and the Member States are working closely together in a spirit of partnership to ensure a coherent and efficient transposition of the Directive into national legislation. During the process of implementation of the Directive, there will also be close contacts with the gas industry, gas sector regulators, consumer associations and other interested parties.

The change from closed to liberalized markets will present both customers and gas companies with new challenges and opportunities. The role of Government here is to ensure, that markets are working efficiently and giving true signals to guide the participants in interpreting and managing change, while maintaining the appropriate level of security of supply.

The Groningen field is an asset value for the Dutch gas industry. The Dutch gas sector often presents itself as "Hub Holland" largely due to the flexibility characteristics of the Groningen field, which will benefit the EU gas consumers in general and play an important role also in the context of the EU single gas market. 